Pacific Journal of Mathematics

UNIFORMLY NORMAL STRUCTURE AND RELATED
COEFFICIENTS

E. MADURA 


\title{
UNIFORMLY NORMAL STRUCTURE AND RELATED COEFFICIENTS
}

\author{
E. Maluta
}

\begin{abstract}
It is shown that uniformly normal structure implies reflexivity. In spaces with uniformly normal structure some estimates are given for the uniformity constant and for a related coefficient.
\end{abstract}

1. Introduction. Our aim is to study two constants of a Banach space $X$ connected with normal structure. We recall that a normed space (or a convex subset) $X$ is said to have normal structure if for every convex bounded non-empty non-singleton subset $C$ of $X$, the Chebyshev radius of $C$ relative to $C, r(C, C)$, is strictly smaller than the diameter of $C$. This concept was introduced by Brodskii and Mil'man (1948), who also gave the following characterization in terms of sequences. A space $X$ has normal structure if and only if there exists in $X$ no bounded non-constant sequence $\left\{x_{n}\right\}$ such that $d\left(x_{n}, \operatorname{co}\left\{x_{j}\right\}_{1}^{n-1}\right)$, i.e. the distance from the $n$th element of the sequence to the convex hull of the preceding elements, approaches the diameter of the sequence as $n$ approaches infinity. (For normal type structures and their applications to fixed point theory, we refer to the exhaustive survey of Kirk [9].)

The first constant we consider, $\tilde{N}(X)$, is the already known constant of uniformity of normal structure. It has a clear geometrical meaning, for it is the supremum, taken with respect to the convex bounded subsets $C$ of $X$, of the ratio between $r(C, C)$ and the diameter of $C$. Hence $\tilde{N}(X)<1$ characterizes uniformly normal structure. The second constant, $D(X)$, is a sequence coefficient which controls the behavior, as $n$ approaches infinity, of $d\left(x_{n}, \operatorname{co}\left\{x_{j}\right\}_{1}^{n-1}\right)$; more precisely, $D(X)$ describes how closely this distance can approach the diameter of the sequence.

For the two constants we give some evaluations and estimates. We prove they both must be one in nonreflexive spaces, thus answering in the affirmative the following question raised in [9]. Does uniformly normal structure imply reflexivity? This question follows naturally from the fact that in [4] it was proved, without requiring any hypothesis of reflexivity, that a space $X$ with $\tilde{N}(X)<1$ has the fixed point property for nonexpansive mappings.

We prove also that, in infinite-dimensional spaces, $\tilde{N}(X) \geq 2^{-1 / 2}$, thus showing that the best value of $\tilde{N}(X)$ is achieved by the space $l^{2}$, and 
we show that in reflexive spaces the gap between $D(X)$ and $\tilde{N}(X)$ can be large. In particular, the property $D(X)<1$ does not characterize uniformly normal structure, yet it is sufficient to assure reflexivity and normal structure, thus the fixed point property for nonexpansive mappings.

2. Notation. In this paper $X$ will always denote a real or complex Banach space. For subsets $A$ and $B$ of $X$, we write $d(A, B)$ for $\inf \{\|x-y\|, x \in A, y \in B\}, \delta(A)$ for the diameter of $A$ and $\operatorname{co} A$ for the convex hull of $A$.

To simplify notation we state the following rules: $\left\{x_{n}\right\}$ will always denote a bounded non-constant sequence in $X$, and $\left\{x_{n}\right\}_{k}^{h}$ will denote the set of elements of $\left\{x_{n}\right\}$ with $k \leq n \leq h$; by $\left\{W_{\alpha}\right\}(\alpha \in \Lambda)$ we mean a decreasing net of bounded nonempty, non-singleton subsets of $X$.

For Chebyshev radii and centers we use the notation

$$
\begin{aligned}
r(A, x) & =\sup \{\|x-y\|: y \in A\}, \\
r(A, B) & =\inf \{r(A, x): x \in B\}, \quad r(A)=r(A, X), \\
\mathcal{C}(A, B) & =\{x \in B: r(A, x)=r(A, B)\}, \quad \mathcal{C}(A)=\mathcal{C}(A, X) ;
\end{aligned}
$$

and for asymptotic diameters and radii,

$$
\begin{gathered}
\delta_{a}\left(\left\{W_{\alpha}\right\}\right)=\inf \left\{\delta\left(W_{\alpha}\right): \alpha \in \Lambda\right\}, \\
r_{a}\left(\left\{W_{\alpha}\right\}, A\right)=\inf \left\{r\left(W_{\alpha}, A\right): \alpha \in \Lambda\right\} .
\end{gathered}
$$

In particular, for a sequence $\left\{x_{n}\right\}$ we have

$$
\begin{aligned}
\delta_{a}\left(\left\{x_{n}\right\}\right) & =\lim _{k} \sup \left\{\left\|x_{n}-x_{m}\right\|: n, m \geq k\right\}, \\
r_{a}\left(\left\{x_{n}\right\}, x\right) & =\lim \sup _{n}\left\|x_{n}-x\right\|, \\
r_{a}\left(\left\{x_{n}\right\}, A\right) & =\inf \left\{r\left(\left\{x_{n}\right\}, x\right): x \in A\right\} .
\end{aligned}
$$

We also recall the definition of modulus of convexity of $X, \delta_{X}$ : $[0,2] \rightarrow[0,1]$, defined by

$$
\delta_{X}(\varepsilon)=\inf \left\{1-\frac{1}{2}\|x+y\|: x, y \in X,\|x\| \leq 1,\|y\| \leq 1,\|x-y\| \geq \varepsilon\right\} .
$$

Furthermore, when there is no possible ambiguity, we write $\lim a_{n}$ instead of $\lim _{n} a_{n}$.

3. Definitions. We now introduce the two constants of a space $X$ we are going to study in this paper. 
Definition 3.1. For a Banach space $X$ we define $D(X)$ as $D(X)=\sup \left\{\frac{\limsup d\left(x_{n+1}, \operatorname{co}\left\{x_{j}\right\}_{1}^{n}\right)}{\delta\left(\left\{x_{n}\right\}\right)}:\left\{x_{n}\right\} \subset X\right.$, $\left\{x_{n}\right\}$ a bounded non-constant sequence in $X$, as established in notation $\}$.

\section{DEFINITION 3.2. We set}

$$
\begin{aligned}
\tilde{N}(X)=\sup \left\{\frac{r(C, C)}{\delta(C)}:\right. & C \text { a bounded non-empty, } \\
& \text { non-singleton convex subset of } X\} .
\end{aligned}
$$

We start with a few simple remarks. Of course $0 \leq D(X) \leq 1$ and $\frac{1}{2} \leq \tilde{N}(X) \leq 1$. In the definition of $D(X)$ we could not consider the limit of $d\left(x_{n+1}, \operatorname{co}\left\{x_{j}\right\}_{1}^{n}\right)$, since nothing can be said, in general, about its existence (consider e.g. in the sequence space $c_{0}$ the sequence $\left\{a_{k} e_{k}\right\}$, where $\left\{e_{k}\right\}$ denotes the natural basis of $c_{0}, a_{k}=1$ for $k$ even and $a_{k}=1 / k$ for $k$ odd).

In order to obtain estimates on $D(X)$, we prove that $D(X)$ can be defined in several equivalent ways. Each of these definitions will be useful in proving some of the following results.

Proposition 3.1.

$$
D(X)=\sup \left\{\frac{\liminf d\left(x_{n+1}, \operatorname{co}\left\{x_{j}\right\}_{1}^{n}\right)}{\delta\left(\left\{x_{n}\right\}\right)}:\left\{x_{n}\right\} \subset X\right\} .
$$

Proof. For every $\left\{x_{n}\right\} \subset X$, set $\alpha=\lim \sup d\left(x_{n}, \operatorname{co}\left\{x_{j}\right\}_{1}^{n-1}\right)$. Then for subsequences $\left\{x_{n_{k}}\right\}$ such that $\alpha=\lim d\left(x_{n_{k}}, \operatorname{co}\left\{x_{j}\right\}_{1}^{n_{k}-1}\right)$ we have

$$
\liminf d\left(x_{n_{k}}, \operatorname{co}\left\{x_{n_{j}}\right\}_{1}^{k-1}\right) \geq \lim d\left(x_{n_{k}}, \operatorname{co}\left\{x_{j}\right\}_{1}^{n_{k}-1}\right)=\alpha .
$$

So, for every $\left\{x_{n}\right\}$ we can find a sequence $\left\{y_{n}\right\} \quad\left(=\left\{x_{n_{k}}\right\}\right.$, hence with $\left.\delta\left(\left\{y_{n}\right\}\right) \leq \delta\left(\left\{x_{n}\right\}\right)\right)$ such that

$$
\frac{\liminf d\left(y_{n+1}, \operatorname{co}\left\{y_{j}\right\}_{1}^{n}\right)}{\delta\left(\left\{y_{n}\right\}\right)} \geq \frac{\limsup d\left(x_{n+1}, \operatorname{co}\left\{x_{j}\right\}_{1}^{n}\right)}{\delta\left(\left\{x_{n}\right\}\right)}
$$

This proves our assertion. 
Proposition 3.2. For a reflexive space $X$,

$$
\begin{aligned}
& D(X) \sup \left\{\frac{\lim \sup d\left(x_{n+1}, \operatorname{co}\left\{x_{j}\right\}_{1}^{n}\right)}{\delta\left(\left\{x_{n}\right\}\right)}:\left\{x_{n}\right\}\right. \text { a weakly } \\
&\text { convergent sequence in } X\} .
\end{aligned}
$$

Proof. For every $\left\{x_{n}\right\} \subset X$, consider a weakly convergent subsequence $\left\{x_{n_{k}}\right\}$. For every $k$ we have

$$
d\left(x_{n_{k}}, \operatorname{co}\left\{x_{n_{j}}\right\}_{1}^{k-1}\right) \geq d\left(x_{n_{k}}, \operatorname{co}\left\{x_{j}\right\}_{1}^{n_{k}-1}\right)
$$

hence

$$
\frac{\limsup d\left(x_{n_{k}}, \operatorname{co}\left\{x_{n_{\jmath}}\right\}_{1}^{k-1}\right)}{\delta\left(\left\{x_{n_{k}}\right\}\right)} \geq \frac{\liminf d\left(x_{n+1}, \operatorname{co}\left\{x_{\jmath}\right\}_{1}^{n}\right)}{\delta\left(\left\{x_{n}\right\}\right)}
$$

so Proposition 3.2 is a consequence of Proposition 3.1.

PROPOSITION 3.3

$$
\begin{aligned}
D(X) & \sup \left\{\frac{\lim \sup d\left(x_{n+1}, \operatorname{co}\left\{x_{j}\right\}_{1}^{n}\right)}{\delta_{a}\left(\left\{x_{n}\right\}\right)}:\right. \\
& \left.\left\{x_{n}\right\} \text { a non-convergent sequence in } X\right\} .
\end{aligned}
$$

Proof. We have, for every non-convergent sequence $\left\{x_{n}\right\}$ and for every $k$.

$$
\limsup d\left(x_{n+1}, \operatorname{co}\left\{x_{J}\right\}_{1}^{n}\right) \leq \limsup d\left(x_{n+1}, \operatorname{co}\left\{x_{j}\right\}_{k}^{n}\right) \leq D(X) \delta\left(\left\{x_{J}\right\}_{k}^{\infty}\right)
$$

so

$$
\begin{aligned}
\limsup _{n} d\left(x_{n+1}, \operatorname{co}\left\{x_{n}\right\}_{1}^{n}\right) & \leq \lim _{k} \limsup _{n} d\left(x_{n+1}, \operatorname{co}\left\{x_{j}\right\}_{k}^{n}\right) \\
& \leq D(X) \delta_{a}\left(\left\{x_{n}\right\}\right) .
\end{aligned}
$$

From this and the inequality $\delta_{a}\left(\left\{x_{n}\right\}\right) \leq \delta\left(\left\{x_{n}\right\}\right)$ we have

$$
D(X) \geq \sup \left\{\frac{\lim \sup d\left(x_{n+1}, \operatorname{co}\left\{x_{j}\right\}_{1}^{n}\right)}{\delta_{a}\left(\left\{x_{n}\right\}\right)}\right\} \geq D(X) .
$$


Proposition 3.4. For an infinite-dimensional reflexive space $X$,

$$
\begin{aligned}
& D(X)=\sup \left\{\frac{\limsup d\left(x_{n+1}, \operatorname{co}\left\{x_{j}\right\}_{1}^{n}\right)}{\delta_{a}\left(\left\{x_{n}\right\}\right)}:\left\{x_{n}\right\}\right. \text { a weakly but not } \\
& \text { strongly convergent sequence in } X\} \text {. }
\end{aligned}
$$

Proof. Use Proposition 3.2 and the same argument used in Proposition 3.3.

4. Main results about $D(X)$ and $\tilde{N}(X)$. We begin proving some results on possible values of $D(X)$.

TheOREM 4.1. $D(X)=0$ if and only if $X$ is a finite-dimensional space. Moreover, if $X$ is an infinite-dimensional space, we have $D(X) \geq$ $\frac{1}{2}\left(1-\delta_{X}(1)\right)^{-1} \geq \frac{1}{2}$. (In particular, $D(X)>\frac{1}{2}$ in uniformly convex spaces.)

Proof. To prove that $\operatorname{dim} X<\infty$ implies $D(X)=0$, it is enough to remark that, for every convergent sequence $\left\{x_{n}\right\}$, we have $\lim d\left(x_{n+1}, \operatorname{co}\left\{x_{\jmath}\right\}_{1}^{n}\right)=0$. This, by Proposition 3.2, proves our claim. If $X$ is an infinite-dimensional space, for every $\theta<1$, let us build a sequence in the following way: $x_{1}$ is an element belonging to $S(0,1)=\{x \in X$ : $\|x\|=1\}$; for every $n \geq 1, x_{n+1}$ is an element of $S(0,1)$ such that $d\left(x_{n+1}, \operatorname{span}\left\{x_{j}\right\}_{1}^{n}\right)>\theta$ (such an element must exist by Riesz's lemma of quasi-orthogonality). Then, for any $i, j, i \neq j$, we have $\left\|x_{l}+x_{j}\right\|>\theta$ so $\frac{1}{2}\left\|x_{\imath}-x_{j}\right\| \leq 1-\delta_{X}(\theta)$. Hence

$$
\frac{\limsup d\left(x_{n+1}, \operatorname{co}\left\{x_{J}\right\}_{1}^{n}\right)}{\delta\left(\left\{x_{n}\right\}\right)} \geq \frac{\theta}{2\left(1-\delta_{X}(\theta)\right)} .
$$

Since $\theta<1$ is arbitrary and $\delta_{X}$ is continuous at 1 , we obtain

$$
D(X) \geq \frac{1}{2}\left(1-\delta_{X}(1)\right)^{-1} \text {. }
$$

Concerning spaces having $D(X)=1$, we recall that this equality holds whenever $X$ lacks normal structure, as a consequence of the existence in $X$ of sequences such that $\lim d\left(x_{n+1}, \operatorname{co}\left\{x_{j}\right\}_{1}^{n}\right)=\delta\left(\left\{x_{n}\right\}\right)$ (we refer to [9] for properties of this kind and their relations with fixed point theory). Moreover the supremum in Definition 3.1 may be achieved by some sequences. We remark that we can find the "worst" situation, i.e. $d\left(x_{n+1}, \operatorname{co}\left\{x_{j}\right\}_{1}^{n}\right)=\delta\left(\left\{x_{n}\right\}\right)$, for every $n$, for some sequences, even in a 
superreflexive space. For instance, let $l^{2}$ be renormed with James's norm, $|x|=\max \left(\|x\|_{2}, 2^{1 / 2}\|x\|_{\infty}\right)$. Then for the natural basis $\left\{e_{n}\right\}$ we have $d\left(x_{n+1}, \operatorname{co}\left\{x_{j}\right\}_{1}^{n}\right)=\delta\left(\left\{x_{n}\right\}\right)=2^{1 / 2}$.

Furthermore, $D(X)$ may be one even in spaces which do have normal structure. While this will be clear for nonreflexive spaces as a consequence of Theorem 4.7, we can give an example also for reflexive spaces.

EXAmple 4.1. Let $X$ be the $l^{2}$ product of the $l^{n}$ spaces, $n \geq 2 ; X$ is reflexive and uniformly convex in every direction, so it has normal structure (see e.g. [3]). Yet $D(X)=1$. In fact, consider in each $l^{p}$, $1<p<\infty$, the usual basis $\left\{e_{n}\right\}$. We have $\delta\left(\left\{e_{n}\right\}\right)=2^{1 / p}$ and $\lim d\left(e_{n+1}, \operatorname{co}\left\{e_{j}\right\}_{1}^{n}\right)=1$, so $D\left(l^{p}\right) \geq 2^{-1 / p}$. For every $n \geq 2$, since there exists a subspace of $X$ isometrically isomorphic to $l^{n}$, we obtain $2^{-1 / n} \leq$ $D\left(l^{n}\right) \leq D(X)$; hence $D(X)=1$.

We come now to the coefficient $\tilde{N}(X)$, which has already been used by several authors in fixed point theory; in particular, it is the inverse of Bynum's $N(X)$ ([2]). If $\tilde{N}(X)<1, X$ is said to have uniformly normal structure. Many authors have already remarked that this is the case, for instance, if $X$ is a uniformly convex space.

THEOREM 4.2. $D(X) \leq \tilde{N}(X)$.

Proof. For every $\left\{x_{n}\right\} \subset X$, let $C$ be $\operatorname{co}\left\{x_{n}\right\}_{1}^{\infty}$. We have $\delta(C)=\delta\left(\left\{x_{n}\right\}\right)$ and $r(C, x)=r\left(\left\{x_{n}\right\}, x\right)$ for every $x \in X$. If $c \in C, c=\Sigma_{1}^{N} \lambda_{l} x_{l}\left(\lambda_{l} \geq 0\right.$, $\left.\Sigma_{1}^{N} \lambda_{l}=1\right)$, then

$$
\begin{aligned}
r\left(\left\{x_{n}\right\}, c\right) & =\sup _{n} d\left(x_{n}, \sum_{1}^{N} \lambda_{l} x_{i}\right) \geq \underset{n}{\lim \sup } d\left(x_{n}, \operatorname{co}\left\{x_{l}\right\}_{1}^{N}\right) \\
& \geq \limsup d\left(x_{n}, \operatorname{co}\left\{x_{i}\right\}_{1}^{n-1}\right) .
\end{aligned}
$$

Hence we obtain

$$
r(C, C)=r\left(\left\{x_{n}\right\}, C\right) \geq \lim \sup d\left(x_{n+1}, \operatorname{co}\left\{x_{l}\right\}_{1}^{n}\right)
$$

and

$$
\tilde{N}(X) \geq \sup \left\{\frac{r(C, C)}{\delta(C)}: C=\operatorname{co}\left\{x_{n}\right\}_{1}^{\infty}\right\} \geq D(X) .
$$

THEOREM 4.3. In any Hilbert space and in two-dimensional spaces, $\tilde{N}(X)=\frac{1}{2} J(X)$, where $J(X)$ is the Jung constant of $X$. As a consequence we obtain $\tilde{N}\left(l_{n}^{2}\right)=(n /(2 n+2))^{1 / 2}$ for Euclidean spaces $l_{n}^{2}$ and $\tilde{N}\left(l^{2}\right)=$ $2^{-1 / 2}$. 
Proof. By a classical result of Garkavi and Klee, we have $\mathcal{C}(C) \cap \bar{C}$ $\neq \varnothing$ for any bounded convex non-empty subset $C$ of $X$, if and only if $X$ is an Hilbert space or a two-dimensional space. In both cases we then have $r(C, C)=r(C)$. The assertion now follows from the definition of Jung's constant and its evaluations in $l_{n}^{2}$ and in (real or complex) $l^{2}$ (see [12]).

As for $D(X)$, we use the following lemma to show that $D(X)$ can be evaluated in any Hilbert space, separable or not.

LEMMA 4.1. For every Banach space $X$, there exists a separable subspace $Y$ of $X$ such that $D(X)=D(Y)$.

Proof. Take a monotone increasing sequence $\left\{d_{k}\right\}$ converging to $D(X)$. For every $k$ there exists a sequence $\left\{x_{n}^{k}\right\}$ such that

$$
\frac{\limsup d\left(x_{n+1}^{k}, \operatorname{co}\left\{x_{J}^{k}\right\}_{1}^{n}\right)}{\delta\left(\left\{x_{n}^{k}\right\}\right)}>d_{k} \text {. }
$$

Set $Y=\operatorname{span}\left\{x_{n}^{k}\right\}, k=1,2, \ldots ; n=1,2, \ldots ; Y$ is separable and $D(Y)$ $=D(X)$.

TheOREM 4.4. For every infinite-dimensional Hilbert space, $D(X)=$ $2^{-1 / 2}$.

Proof. By Lemma 4.1, $D(X)=D\left(l^{2}\right)$, which is $2^{-1 / 2}$ as a consequence of Theorems 4.2, 4.3 and the estimation from below of $D\left(l^{p}\right)$ obtained in Example 4.1.

In general Banach spaces it seems very difficult to evaluate $\tilde{N}(X)$. Yet we can give some interesting estimations from below.

THEOREM 4.5. In every infinite-dimensional Banach space, $\tilde{N}(X) \geq$ $2^{-1 / 2}$.

To prove the theorem, we need:

LEMMA 4.2. If $X$ and $Y$ are isomorphic Banach spaces, then

$$
[d(X, Y)]^{-1} \tilde{N}(X) \leq \tilde{N}(Y) \leq d(X, Y) \tilde{N}(X),
$$

where $d(X, Y)$ denotes the Banach-Mazur distance from $X$ to $Y$. 
An analogous result holds for $D(X)$. The lemma is an easy consequence of the definitions of Banach-Mazur distance and of $\tilde{N}(X)$, and has already been used by Bynum for his $N(X)$.

Proof of Theorem 4.5: By a classical result of Dvoretsky (see e.g. [3]), if $X$ is an infinite-dimensional Banach space, for every integer $n$ and for every $\varepsilon>0$, we can find a subspace $Y$ of $X$ isomorphic to the Euclidean $n$-dimensional space $l_{n}^{2}$, with $d\left(Y, l_{n}^{2}\right) \leq 1+\varepsilon$. Now fix $n$, and, for every $\varepsilon>0$, consider $Y_{\varepsilon} \subset X$ such that $d\left(Y_{\varepsilon}, l_{n}^{2}\right) \leq 1+\varepsilon$. By Lemma 4.2 and Theorem 4.3 we have

$$
\frac{1}{1+\varepsilon}\left(\frac{n}{2 n+2}\right)^{1 / 2} \leq \tilde{N}\left(Y_{\varepsilon}\right) \leq \tilde{N}(X) \text { for every } \varepsilon
$$

hence $(n /(2 n+2))^{1 / 2} \leq \tilde{N}(X)$. Since $n$ is arbitrary, we obtain $2^{-1 / 2} \leq$ $\tilde{N}(X)$.

THEOREM 4.6. $\tilde{N}(X)=\frac{1}{2}$ if $X=\left(R^{2},\|\cdot\|_{\infty}\right)$, but $\tilde{N}(X)>\frac{1}{2}$ if the dimension of $X$ is greater than two.

Proof. The first part of our theorem follows from Theorem 4.3 and the evaluation $J(X)=1$ in real $L^{\infty}(\mu)$ spaces ([6]).

For the second part, as a consequence of Theorems 4.3 and 4.5, we have only to prove the thesis for any finite-dimensional space $X, X \neq l_{n}^{2}$, with $\operatorname{dim} X \geq 3$. Under these hypotheses there exists a bounded closed convex non-empty set $C$ such that $\mathcal{C}(C) \cap C=\varnothing$ (see the proof of Theorem 4.3). Yet, by a compactness argument, both $\mathcal{C}(C, C)$ and $\mathcal{C}(C)$ are non-empty and this implies $r(C, C)>r(C) \geq \frac{1}{2} \delta(C)$.

If $X$ is a non-reflexive space, we can evaluate both $D(X)$ and $\tilde{N}(X)$.

THEOREM 4.7. If $X$ is a non-reflexive Banach space, then $D(X)=1$.

Proof. By a result of Mil'man and Mil'man ([11]), we can say that if $X$ is a non-reflexive space, then, for every $\varepsilon>0$, there exists a sequence $\left\{x_{n}\right\}$ such that $1-\varepsilon \leq\left\|u_{1 n}-u_{n \omega}\right\| \leq 1+\varepsilon$ for any $u_{1 n} \in \operatorname{co}\left\{x_{j}\right\}_{1}^{n}, u_{n \omega} \in$ $\operatorname{co}\left\{x_{J}\right\}_{n+1}^{\infty}$, and for any $n$. Then $\delta\left(\left\{x_{n}\right\}\right) \leq 1+\varepsilon$ and $d\left(x_{n+1}, \operatorname{co}\left\{x_{J}\right\}_{1}^{n}\right) \geq$ $1-\varepsilon$. Hence it follows that $D(X) \geq 1$.

An immediate consequence of this theorem, taking into account Theorem 4.2, is:

COROllary 4.1. If $X$ is a non-reflexive Banach space, then $\tilde{N}(X)=1$. 
The corollary answers in the affirmative the following question raised in [9]. Does uniformly normal structure imply reflexivity? Moreover Theorem 4.7 allows us to claim

TheOREM 4.8. If $D(X)<1$, then $X$ has the fixed point property for non-expansive mappings with respect to closed bounded convex subsets.

In fact, $D(X)<1$ implies reflexivity and normal structure, so the result follows from [8]. Furthermore, we show in $\S 5$ that $D(X)<1$ does not imply $\tilde{N}(X)<1$, so Theorem 4.8 is not contained in the theorem of Gillespie and Williams ([4]).

COROllaRY 4.2. If $\tilde{N}(Y)<1$ for every separable subspace $Y$ of $X$, then $X$ has the fixed point property for nonexpansive mappings with respect to closed bounded convex subsets.

Proof. Theorem 4.2 and Lemma 4.1 show that $D(X)<1$.

REMARK 4.1. For Banach spaces which contain subspaces isomorphic to $c_{0}$ or $l^{1}$, so, in particular, for non-reflexive spaces with an unconditional basis, Theorem 4.7 can be proved as a consequence of James's theorem ([7]) on the nearly isometric embedding of $c_{0}$ or $l^{1}$ in $X$.

REMARK 4.2. The "stability" under renorming we proved for $D(X)$ and $N(X)$ in non-reflexive spaces is quite surprising. In fact, the usual situation for normal type structure is a strong dependence from the norm. Consider, for instance, $l^{2}$ with a Hilbert norm and James's norm (see $\mathrm{p}$. 361). Furthermore, it has been proved that normal structure can be induced on every separable Banach space by a suitable renorming (see [3], [9]), while, of course, nothing similar is true for uniformly normal structure.

5. Relations with Bynum's normal structure coefficients. Now we are going to explore relations among $D(X)$ and some coefficients defined, for reflexive spaces, by Bynum ([2]). We have already remarked that $\tilde{N}(X)$ is the inverse of Bynum's $N(X)$, i.e.,

$$
N(X)=\inf \left\{\frac{\delta(C)}{r(C, C)}: C\right. \text { a convex bounded non-empty, }
$$

non-singleton subset of $X\}$. 
We recall also that

$$
B S(X)=\inf \left\{\frac{\delta_{a}\left(\left\{x_{n}\right\}\right)}{r_{a}\left(\left\{x_{n}\right\}, \operatorname{co}\left\{x_{n}\right\}\right)}:\left\{x_{n}\right\} \text { a non-convergent sequence in } X\right\}
$$

and $W C S(X)$ is defined as $B S(X)$ but with the infimum taken with respect only to weakly but not strongly convergent sequences.

$N(X)$ and $B S(X)$ can be defined in every Banach space; $W C S(X)$, on the contrary, is well defined only in infinite-dimensional reflexive spaces, where, by the Eberlein-Šmulian theorem, we can assure the existence of weakly convergent sequences which do not converge.

Bynum proved that, in reflexive spaces, $1 \leq N(X) \leq B S(X) \leq$ $W C S(X) \leq 2$. Furthermore, we have:

THEOREM 5.1. In infinite-dimensional reflexive spaces $D(X) \leq$ $1 / W C S(X)$.

Proof. On account of Proposition 3.4, it is enough to prove that

$\limsup d\left(x_{n+1}, \operatorname{co}\left\{x_{J}\right\}_{1}^{n}\right) \leq r_{a}\left(\left\{x_{n}\right\}, \operatorname{co}\left\{x_{n}\right\}\right)$ for every $\left\{x_{n}\right\}$ in $X$.

Let $x \in \operatorname{co}\left\{x_{n}\right\}, x=\Sigma_{1}^{N} \lambda_{J} x_{J}\left(\lambda_{J} \geq 0, \Sigma_{1}^{N} \lambda_{J}=1\right)$. Then

$$
\begin{aligned}
r_{a}\left(\left\{x_{n}\right\}, x\right) & =\lim \sup \left\|x_{n}-x\right\| \geq \lim \sup d\left(x_{n+1}, \operatorname{co}\left\{x_{J}\right\}_{1}^{N}\right) \\
& \geq \lim \sup d\left(x_{n+1}, \operatorname{co}\left\{x_{j}\right\}_{1}^{n}\right) .
\end{aligned}
$$

Remark 5.1. An analogous argument and Proposition 3.3 give $D(X)$ $\leq 1 / B S(X)$ in any Banach space. So in particular, as a consequence of Theorem 4.7, $B S(X)=1$ in non-reflexive spaces.

ReMark 5.2. It is not clear whether $D(X)$ and $1 / W C S(X)$ must coincide in every infinite-dimensional reflexive space.

Bynum showed that $B S\left(l^{2}\right)=W C S\left(l^{2}\right)=2^{1 / 2}$. We can argue as in Lemma 4.1 to say that, for every $X$, there exists a separable subspace $Y$ such that $B S(X)=B S(Y)(W C S(X)=W C S(Y))$. So we obtain

COROllary 5.1. In every infinite-dimensional Hilbert space $B S(X)=$ $\operatorname{WCS}(X)=2^{1 / 2}$.

In infinite-dimensional Hilbert spaces, both $D(X)$ and $1 / W C S(X)$ must be $2^{-1 / 2}$. Yet this property is not characteristic of Hilbert spaces. 
EXAMPLE 5.1. Let $X$ be the $l^{2}$ product of the spaces $l_{n}^{\infty}=\left(R^{n},\|\cdot\|_{\infty}\right)$, $n \geq 1$. Baillon proved that $W C S(X)=2^{1 / 2}([11])$. Moreover consider the sequence $\left\{x_{n}\right\} \subset X$, where, for each $x_{n}$, the only non-zero coordinate is the $n$th and this one is the vector $(1,0, \ldots, 0)$ of $R^{n}$. Then $\delta\left(\left\{x_{n}\right\}\right)=2^{1 / 2}$ and $\lim d\left(x_{n+1}, \operatorname{co}\left\{x_{j}\right\}_{1}^{n}\right)=1$, so $D(X) \geq 2^{-1 / 2}$. From Theorem 5.1 it follows that $D(X)=1 / W C S(X)=2^{-1 / 2}$, yet $X$ cannot be a Hilbert space because it has subspaces isometrically isomorphic to $l_{n}^{\infty}$.

Baillon also proved that, for the space $X$ of our last example, $N(X)$ is one. So we obtain:

Corollary 5.2. $D(X)<1$ does not characterize uniformly normal structure.

For more results about characterizations of normal type structures by means of sequences, see [10].

From Theorem 5.1, combining Bynum's evaluation of $\operatorname{WCS}\left(l^{p}\right)$ with the lower bound for $D\left(l^{p}\right)$ we obtained in Example 4.1, we have:

THEOREM 5.2. $D\left(l^{p}\right)=2^{-1 / p}$ for $1<p<\infty$.

At first sight we could think that we have to construct suitable spaces to find a big gap between $D(X)$ or $1 / W C S(X)$ and $\tilde{N}(X)$, as we did in Example 5.1. On the contrary, if we do not require $\tilde{N}(X)=1$, this is the case also for some classical spaces (and obviously for the finite-dimensional ones). In fact, taking into account Theorems 4.5 and 5.2, we obtain:

Corollary 5.3. $D\left(l^{p}\right)=1 / W C S\left(l^{p}\right)<\tilde{N}\left(l^{p}\right)$ for $1<p<2$.

REMARK 5.3. The lower bound given by Bynum for his $N(X)$ using the modulus of convexity of $X$, namely $N(X) \geq\left(1-\delta_{X}(1)\right)^{-1}$, and the analogous bound we obtained in Theorem 4.1 for $D(X)$, are not candidates for the actual values of $N(X)$ and $D(X)$, not even if $X$ is a uniformly convex space. In fact, $N\left(l^{2}\right)=1 / D\left(l^{2}\right)=2^{1 / 2}$, while, using Hanner's estimates of the modulus of convexity in $L^{p}$ spaces ([5]), we obtain $1-\delta_{l^{2}}(1)=3^{1 / 2} / 2$.

We can also give the following equivalent definition for $N(X)$, thus obtaining immediately, and without any hypothesis of reflexivity on $X$, Theorem 1 of [2]. 
Proposition 5.1.

$$
N(X)=\inf \left\{\frac{\delta_{a}\left(\left\{W_{\alpha}\right\}\right)}{r_{a}\left(\left\{W_{\alpha}\right\}, \operatorname{co}\left\{W_{\alpha}\right\}\right)}:\left\{W_{\alpha}\right\} \subset 2^{X}\right\} .
$$

Proof. To simplify notation we call the right-hand side of the equality $W(X)$. The inequality $N(X) \geq W(X)$ follows immediately by taking, among nets $\left\{W_{\alpha}\right\} \subset 2^{X}$, nets such that $W_{\alpha}=C$ for every $\alpha$, where $C$ is a bounded convex non-empty, non-singleton subset of $X$. Vice versa, for each set $W_{\alpha} \in\left\{W_{\alpha}\right\}$,

$$
N(X) \leq \frac{\delta\left(\operatorname{co} W_{\alpha}\right)}{r\left(\operatorname{co} W_{\alpha}, \operatorname{co} W_{\alpha}\right)} \leq \frac{\delta\left(W_{\alpha}\right)}{r\left(W_{\alpha}, \operatorname{co}\left\{W_{\alpha}\right\}\right)} \leq \frac{\delta\left(W_{\alpha}\right)}{r_{a}\left(\left\{W_{\alpha}\right\}, \operatorname{co}\left\{W_{\alpha}\right\}\right)} .
$$

Hence

$$
N(X) \leq \frac{\delta_{a}\left(\left\{W_{\alpha}\right\}\right)}{r_{a}\left(\left\{W_{\alpha}\right\}, \operatorname{co}\left\{W_{\alpha}\right\}\right)} .
$$

This holds for every $\left\{W_{\alpha}\right\}$ so $N(X) \leq W(X)$.

The author wishes to thank P. Papini for many useful remarks and for calling her attention to [2] and [11].

\section{REFERENCES}

[1] J.-B. Baillon, unpublished.

[2] W. L. Bynum, Normal structure coefficients for Banach spaces, Pacific J. Math., 86 (1980), 427-436.

[3] M. M. Day, Normed Linear Spaces, Springer-Verlag, Berlin, 1973.

[4] A. A. Gillespie and B. B. Williams, Fixed point theorem for nonexpansive mappings on Banach spaces with uniformly normal structure, Appl. Anal., 9 (1979), 121-124.

[5] O. Hanner, On the uniform convexity of $L^{p}$ and $l^{p}$, Ark. Math., 3 (1956), 239-244.

[6] R. B. Holmes, A Course in Optimization and Best Approximation, Lecture Notes in Mathematics, v. 257, Springer-Verlag, Berlin, 1972.

[7] R. C. James, Uniformly non-square Banach spaces, Ann. of Math., 80 (1964), $542-550$.

[8] W. A. Kirk, A fixed point theorem for mappings which do not increase distances, Amer. Math. Monthly, 72 (1965), 1004-1006.

[9] _ Nonexpansive mappings and normal structure in Banach spaces, Proc. of Research Workshop on Banach space theory, The University of Iowa, 1981.

[10] E. Maluta, Characterization of normal type structure by means of sequences, Ist. Lombardo Accad. Sci. Lett. Rend. A, 113 (1979), 436-444. 
[11] D. P. Mil'man and V. D. Mil'man, The geometry of nested families with empty intersection-Structure of the unit sphere of a nonreflexive space, Amer. Math. Soc. Transl., (2) 85 (1969), 233-243.

[12] N. Routledge, A result in Hilbert space, Quart. J. Math., 3 (1952), 12-18.

Received May 26, 1982. Research partially supported by G.N.A.F.A. of C.N.R.

ISTITUTo Di Matematica-Università

Via C. Saldini, 50

20133 Milano, Italy 



\title{
PACIFIC JOURNAL OF MATHEMATICS EDITORS
}

\author{
Donald BABBITT (Managing Editor) \\ University of California \\ Los Angeles, CA 90024 \\ Hugo RossI \\ University of Utah \\ Salt Lake City, UT 84112 \\ C. C. MOore and Arthur Ogus \\ University of California \\ Berkeley, CA 94720
}

J. DUGUNDJI
Department of Mathematics

University of Southern California

Los Angeles, CA 90089-1113

R. FinN and H. SAMELSON

Stanford University

Stanford, CA 94305

\section{ASSOCIATE EDITORS}
R. ARENS
E. F. BECKENBACH
B. H. NeumanN
F. WOLF
K. YosHIDA (1906-1982)

\section{SUPPORTING INSTITUTIONS}

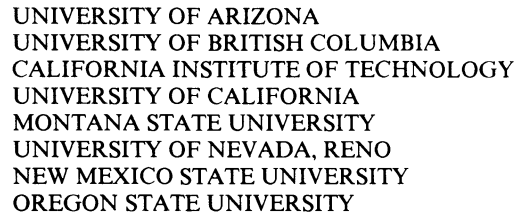

UNIVERSITY OF ARIZONA

UNIVERSITY OF BRITISH COLUMBIA

CALIFORNIA INSTITUTE OF TECHNOLOGY

UNIVERSITY OF CALIFORNIA

MONTANA STATE UNIVERSITY

UNIVERSITY OF NEVADA, RENO

NEW MEXICO STATE UNIVERSITY

OREGON STATE UNIVERSITY

\author{
UNIVERSITY OF OREGON \\ UNIVERSITY OF SOUTHERN CALIFORNIA \\ STANFORD UNIVERSITY \\ UNIVERSITY OF HAWAII \\ UNIVERSITY OF TOKYO \\ UNIVERSITY OF UTAH \\ WASHINGTON STATE UNIVERSITY \\ UNIVERSITY OF WASHINGTON
}

The Supporting Institutions listed above contribute to the cost of publication of this Journal, but they are not owners or publishers and have no responsibility for its content or policies.

Mathematical papers intended for publication in the Pacific Journal of Mathematics should be in typed form or offset-reproduced (not dittoed), double spaced with large margins. Please do not use built up fractions in the text of the manuscript. However, you may use them in the displayed equations. Underline Greek letters in red, German in green, and script in blue. The first paragraph must be capable of being used separately as a synopsis of the entire paper. In particular it should contain no bibliographic references. Please propose a heading for the odd numbered pages of less than 35 characters. Manuscripts, in triplicate, may be sent to any one of the editors. Please classify according to the scheme of Math. Reviews, Index to Vol. 39. Supply name and address of author to whom proofs should be sent. All other communications should be addressed to the managing editor, or Elaine Barth, University of California, Los Angeles, California 90024.

There are page-charges associated with articles appearing in the Pacific Journal of Mathematics. These charges are expected to be paid by the author's University, Government Agency or Company. If the author or authors do not have access to such Institutional support these charges are waived. Single authors will receive 50 free reprints; joint authors will receive a total of 100 free reprints. Additional copies may be obtained at cost in multiples of 50 .

The Pacific Journal of Mathematics is issued monthly as of January 1966. Regular subscription rate: $\$ 132.00$ a year (6 Vol., 12 issues). Special rate: $\$ 66.00$ a year to individual members of supporting institutions.

Subscriptions, orders for numbers issued in the last three calendar years, and changes of address should be sent to Pacific Journal of Mathematics, P.O. Box 969, Carmel Valley, CA 93924, U.S.A. Old back numbers obtainable from Kraus Periodicals Co., Route 100, Millwood, NY 10546.

The Pacific Journal of Mathematics ISSN 0030-8730 is published monthly by the Pacific Journal of Mathematics at P.O. Box 969, Carmel Valley, CA 93924. Application to mail at Second-class postage rates is pending at Carmel Valley, California, and additional mailing offices. Postmaster: Send address changes to Pacific Journal of Mathematics, P. O. Box 969, Carmel Valley, CA 93924.

PUBLISHED BY PACIFIC JOURNAL OF MATHEMATICS, A NON-PROFIT CORPORATION 


\section{Pacific Journal of Mathematics}

\section{Vol. 111, No. $2 \quad$ December, 1984}

Berndt Brenken, Representations and automorphisms of the irrational

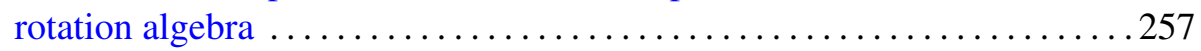

Harold George Diamond, A number theoretic series of I. Kasara . . . . . . 283

Rolf Farnsteiner, On the structure of simple-semiabelian Lie algebras . . . . 287

Guillermo Grabinsky, Poisson process over $\sigma$-finite Markov chains . ......301

Derbiau Frank Hsu and A. Donald Keedwell, Generalized complete

mappings, neofields, sequenceable groups and block designs. I . . . . . 317

William H. Julian and Fred Richman, A uniformly continuous function on

$[0,1]$ that is everywhere different from its infimum $\ldots \ldots \ldots \ldots . \ldots 33$

D. H. Lehmer and Emma Lehmer, The sextic period polynomial .........341

E. Maluta, Uniformly normal structure and related coefficients ...........357

Coy Lewis May, The species of bordered Klein surfaces with maximal

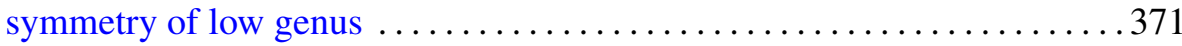

Louis Jackson Ratliff, Jr., On asymptotic prime divisors . . . . . . . . . . . 395

Norbert Riedel, Disintegration of KMS-states and reduction of standard von

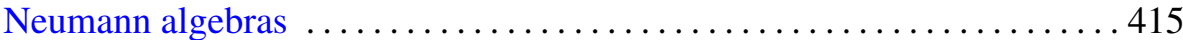

Richard Gordon Swan, $n$-generator ideals in Prüfer domains ...........433

Vilmos Totik, An interpolation theorem and its applications to positive

operators .................................. 447

Richard Vrem, Hypergroup joins and their dual objects 